\title{
Evaluation of the association between HIF-1 $\alpha$ and HER-2 expression, hormone receptor status, Ki-67 expression, histology and tumor FDG uptake in breast cancer
}

\author{
SEVIM SUREYYA CERCI ${ }^{1}$, KEMAL KURSAT BOZKURT ${ }^{2}$, HASAN EROL EROGLU $^{3}$, \\ CELAL CERCI $^{4}$, EVRIM ERDEMOGLU ${ }^{5}$, PINAR TALIP BULBUL ${ }^{1}$, MELTEM CETIN $^{6}$, \\ RECEP CETIN $^{3}$, IBRAHIM METIN CIRIS ${ }^{2}$ and MAHMUT BULBUL ${ }^{7}$
}

\begin{abstract}
Departments of ${ }^{1}$ Nuclear Medicine; ${ }^{2}$ Pathology and ${ }^{3}$ Oncologic Surgery, Süleyman Demirel University Hospital, Isparta 32260;
${ }^{4}$ Department of General Surgery, Sifa Hospital, Isparta 32200; ${ }^{5}$ Department of Gynecologic Oncology, Süleyman Demirel

University Hospital, Isparta 32260; ${ }^{6}$ Department of Radiology, Atatürk Teaching and Research Hospital, University of Kâtip

Celebi, Izmir 35360; ${ }^{7}$ Department of General Surgery, Süleyman Demirel University Hospital, Isparta 32260, Turkey
\end{abstract}

Received November 6, 2015; Accepted August 12, 2016

DOI: $10.3892 / 01.2016 .5199$

\begin{abstract}
The present study aimed to examine hypoxiainducible factor (HIF)-1 $\alpha$ expression and its association with glucose uptake in invasive breast cancer. In addition, connections between glucose uptake and several other prognostic parameters of breast cancer were studied. Between August 2013 and April 2015, 92 patients with biopsy-diagnosed breast cancer were subjected to ${ }^{18} \mathrm{~F}$-fluorodeoxyglucose positron emission tomography/computed tomography. The primary tumor and nodal maximum standardized uptake values (SUVmax) were recorded, and HIF-1 $\alpha$ expression and clinical parameters, including tumor mass, estrogen receptor (ER) and progesterone receptor $(\mathrm{PgR})$ levels, human epidermal growth factor receptor-2 (HER-2), Ki-67 index, grade and histology, were analyzed. SUVmax was compared with clinicopathological parameters and HIF-1 $\alpha$ expression. The median SUVmax values of the ER-negative and PgR-negative tumors were significantly increased compared with ER and PgR-positive tumors, respectively $(\mathrm{P}=0.004$ and $\mathrm{P}=0.008)$. SUVmax differed significantly between the T2 and T3 tumors and the T1 tumors. The median SUVmax levels were higher in the $\mathrm{Ki}-67$ expression $>10 \%$ group than the $\mathrm{Ki}-67$ index $<10 \%$ group $(\mathrm{P}=0.001)$. Although the median SUVmax values in HER-2-positive and -negative tumors were similar, triplenegative tumors demonstrated significantly higher values $(\mathrm{P}=0.04)$. With regard to tumor grade, the median SUVmax was greater in the high-grade tumors compared with the
\end{abstract}

Correspondence to: Dr Sevim Sureyya Cerci, Department of Nuclear Medicine, Süleyman Demirel University Hospital, Çünür, Isparta 32260, Turkey

E-mail: sureyyacerci@hotmail.com

Key words: breast cancer, ${ }^{18} \mathrm{~F}$-fluorodeoxyglucose uptake, hypoxia-inducible factor- $1 \alpha$, prognostic parameters low-grade tumors. SUVmax did not exhibit a significant correlation with HIF-1 $\alpha$ expression; however, HIF-1 $\alpha$ expression was associated with tumor size and PgR expression. HIF-1 $\alpha$ expression increased with a larger tumor size $(\mathrm{r}=0.27 ; \mathrm{P}=0.008)$ and decreased $\mathrm{PgR}$ expression ( $\mathrm{r}=-0.26 ; \mathrm{P}=0.0002)$. The axillary nodal SUVmax of the N1 tumors was significantly lower than the $\mathrm{N} 2$ and $\mathrm{N} 3$ tumors $(\mathrm{P}<0.0001)$. In the multivariate analysis, tumor size, Ki-67 expression and ER Allred score were independent factors that impacted SUVmax. The results of the present study indicated strong associations between tumor size, tumor grade, Ki-67 expression, triple-negativity, downregulated hormone receptor expression and SUVmax values. Conversely, there was no association observed between glucose uptake and levels of HIF-1 $\alpha$. Based on these results, it is suggested that the lack of assiocation between hypoxia and glucose uptake indicates phenotypic independence.

\section{Introduction}

Breast cancer is the most prevalent malignancy in women, accounting for $29 \%$ of all female cancer cases (1). Despite progress in early diagnosis and treatment, breast cancer remains the second most frequent cause of cancer-associated mortality in women in United States (1). Traditionally, histologic tumor grade, tumor size, estrogen receptor (ER) and progesterone receptor (PgR) expression, axillary lymph node involvement, Ki-67 expression and human epidermal growth factor receptor-2 (HER-2) status have been employed as prognostic factors for breast cancer patients.

The association between tumorigenesis, hypoxia and tumor development is well-documented (2). Tumor hypoxia is facilitated by various factors, including tumor localization, tumor size and blood flow, all of which affect oxygen accessibility (3). The most recognized hypoxia signaling factor is hypoxia-inducible factor (HIF)-1 (3). HIF-1 is made up of two subunits: HIF- $1 \alpha$ and HIF-1 $\beta(4,5)$. While HIF-1 $\beta$ is expressed constitutively, HIF- $1 \alpha$ is only expressed during hypoxic conditions and is a measurement of overall activity (4-7). Increased 
levels of HIF-1 $\alpha$ have been documented in multiple tumors, in particular breast cancer (8). Notably, cells under low oxygen stress often switch to aerobic glycolysis (lactate production), a low energy-generating state, from oxidative phosphorylation, which is termed the Warburg effect (9). Previous studies have reported that aerobic glycolysis increases $\sim 2$-fold under acute hypoxia, which results in augmented cytoplasmic hexokinase and membrane-localized glucose transporters (GLUT), including GLUT-1 and GLUT-3 (10). Although hypoxia has been generally recognized for its impact on glucose metabolism, certain hypoxic tumors demonstrate marginal increases in glucose uptake, glycolytic shift and lactate production (9).

Augmented and differential glucose metabolism was established in 1931 by Otto Warburg (11). A measure of glucose uptake is an important feature of the Warburg effect phenomenon and may be measured in tumors with ${ }^{18} \mathrm{~F}$-fluorodeoxyglucose (FDG) tracers and positron emission tomography (PET). FDG-PET provides semiquantitative measurement of glucose standardized uptake value (SUV), which may aid in predicting tumor activity, treatment monitoring, staging and detection of disease recurrence $(12,13)$. The level of FDG uptake in breast tumors has been documented for its heterogeneity compared with other forms of cancer (14). Notably, breast cancer FDG uptake is reported to be associated with several tumorigenic factors, including histologic grade, tumor size and hormone receptor expression levels, among others (15-17). Based on this, breast cancer with augmented glucose uptake is more aggressive compared to breast cancer with low glucose uptake (15-17).

The present study aimed to investigate the association between FDG uptake and HIF-1 $\alpha$ expression in breast cancer. The link between known breast cancer parameters (tumor size, axillary lymph node involvement, ER and PgR expression, HER-2, Ki-67 expression, grade and histology) and FDG uptake was also evaluated.

\section{Materials and methods}

Patient characteristics and tissue samples. A total of 92 patients, who were diagnosed with no particular type of breast carcinoma between August 2013 and April 2015 in the Department of Surgical Oncology, Süleyman Demirel University (Isparta, Turkey), were included in the study. Diagnosis of primary breast cancer was defined by coreneedle biopsy at least 15 days prior to PET/computed tomography (CT). Initial diagnosis and re-analysis of biopsies were performed by a pathologist (Department of Pathology, Süleyman Demirel University) for diagnostic confirmation. The tumors were subjected to the modified Scarff-BloomRichardson grading system (18) and categorized based on the World Health Organization classification system (19). FDG-PET analysis was performed on all 92 patients between August 2013 and April 2015 to determine the stage of the disease prior to therapy. Patients were eligible for surgery if no indication of distant metastatic spread was determined. Patients diagnosed with excisional biopsy and/or lesions $<1 \mathrm{~cm}$ (based on CT images) were not included in the study. Each individual was subjected to surgery three weeks after FDG-PET examination. No patients received neoadjuvant therapy. The study was approved by the Ethics Committee of the Süleyman Demirel Universty and informed consent was obtained from all patients prior to examination.

FDG-PET image acquisition. Whole-body FDG-PET scans were perfomed as described using the Philips Gemini TF PET/CT scanner (Philips Medical Systems B.V., Eindhoven, The Netherlands). Patients were prepared by a 6-h fast, as serum glucose levels had to be $<150 \mathrm{mg} / \mathrm{dl}$ prior to glucose tracer administration. At $60 \mathrm{~min}$ after the intravenous injection of 3.7 $\mathrm{MBq} / \mathrm{kg}(0.1 \mathrm{mCi} / \mathrm{kg}){ }^{18} \mathrm{~F}-\mathrm{FDG}$ (Monrol, Eczacıbaş1, İstanbul, Turkey), PET/CT was performed. Subsequently, an emission scan was recorded in three-dimensional mode following CT for 2 min per position. PET and CT images were examined in the cross-sectional planes view and in the rotating maximumintensity projection. FDG uptake in the tumor and lymph nodes were semiquantified using maximum SUV (SUVmax).

Immunohistochemistry. HIF-1 $\alpha$ expression was evaluated by immunohistochemistry using monoclonal rabbit anti-human HIF-1 $\alpha$ antibodies (clone, EP1215Y; dilution, 1:100; Abcam, Cambridge, MA, USA). A biotynilated goat anti-polyvalent secondary antibody (TP-125-BN; Thermo Fisher Scientific, Inc., Waltham, MA, USA) experiment was run in parallel as a negative control and human ovarian carcinoma was used as positive control. The avidin-biotin-peroxidase complex method was used while performing immunostaining. Immunohistochemistry was performed on formalin-fixed, paraffin-embedded resection specimens. Tissues were kept in $10 \%$ formalin at room temperature for overnight fixation and processed in a fully automated tissue processor. Sections from paraffin-embedded tissues ( $4 \mu \mathrm{m}$ thick) were obtained for immunohistochemical staining. The level of staining was determined using a light microscope. In the evaluation of immunostaining, nuclear immunoreactivity in neoplastic cells was considered as positive. A value $\geq 10 \%$ was set as the cut-off to distinguish positive and negative immunoreactivity (20).

Statistical analysis. Median and interquartile ranges (IQR) for the SUVmax for each prognostic indicator, including hormone receptor expression, Allred score above or below 4, grade 1, 2 vs. grade 3, HIF-1 $\alpha$, HER-2, Ki67 index, histology, and tumor (T1, T2 and T3) and nodal (N0, N1, N2 and N3) status, were calculated (21). SUVmax and prognostic indicators were analyzed by the Mann-Whitney U test or Kruskal Wallis test. Categorical data were studied using the $\chi^{2}$ test. Mean IQR $\left(\mathrm{IQR}_{\mathrm{M}}\right)$ was calculated and used instead of mean \pm standard deviation. Multiple regression analysis was employed using the forward enter method by recruiting predictors with $\mathrm{P}<0.05$ and excluding if $\mathrm{P}>0.10$. Outliers were identified and excluded from analysis. Multiple regression analysis yielded the best predictors of SUVmax. $\mathrm{P}<0.05$ was considered to indicate a statistically significant difference. Statistical analysis was performed using by MedCalc v12.5 (MedCalc Software bvba, Ostend, Belgium).

\section{Results}

Patient characteristics. A total of 92 patients were enrolled in the present study. The mean age was $58.9 \pm 11.5$ years $\left(I_{Q} R_{M}\right.$, 58.3 years). Tumors were determined in the right breast of 35 
(38.0\%) patients and in the left breast of 57 (62.0\%) patients $(\mathrm{P}=0.02)$. The $\mathrm{IQR}_{\mathrm{M}}$ tumor size, number of metastatic lymph nodes, tumor SUVmax and axillary tumor SUVmax were $2.5 \mathrm{~cm}, 2.2,7$ and 2.6, respectively.

Tumor characteristics. The characteristics of all tumors are presented in Table I. The tumors were grade 1,2 and 3 in 16.3, 53.3 and $30.4 \%$ of patients, respectively. In addition, 32.6, 30.4, 21.7 and $15.2 \%$ of patients were $\mathrm{N} 0, \mathrm{~N} 1, \mathrm{~N} 2$ and $\mathrm{N} 3$, respectively, and tumor size was T1, T2 and T3 in 20.7, 69.6 and 9.8\% of patients, respectively. ER was positive in $82.6 \%$ of patients and negative in $17.4 \%$, while PgR was positive in $81.5 \%$ of patients and negative in $18.5 \%$. The $\mathrm{IQR}_{\mathrm{M}}$ estrogen and progesterone Allred scores were 6.2 and 5, respectively. HER-2 expression was classified as $0,1,2$ and 3 in 44.6, 16.3, 14.1 and $25.0 \%$ of patients, respectively. Silver in situ hybridization (SISH) was applied to 13 patients and $7(53.8 \%)$ were positive. A total of $84(91.3 \%)$ patients were triple-negative. Ki-67 expression was $\leq 10 \%$ in $34(37.0 \%)$ patients and $>10 \%$ in $58(63.0 \%)$ patients. HIF-1 $\alpha$ was positive in $83.7 \%$ of patients (Table I; Fig. 1A and B).

Clinicopathological parameters, SUVmax and HIF-1 . Comparisons between SUVmax, HIF-1 $\alpha$ and clinicopathological parameters of the primary tumors are presented in Table II. The median SUVmax values of ER- and PgR-negative tumors were significantly increased $(\mathrm{P}=0.004$ and $\mathrm{P}=0.008)$. This difference in SUVmax was also evident in the Allred score of ER and PgR. The SUVmax values of the T2 and T3 tumors were significantly different from those of the T1 tumors $(\mathrm{P}=0.02)$, and the SUVmax values between the Ki-67 $>10 \%$ group and the Ki-67 $<10 \%$ group were also significantly different $(\mathrm{P}=0.01)$. Although median SUVmax values were not different in HER-2-positive and -negative tumors, it was higher in triple-negative tumors $(\mathrm{P}=0.04)$. With regard to tumor grade, median SUVmax was significantly higher in high-grade tumors (Fig. 2A and B). SUVmax did not exhibit a significant correlation with HIF-1 $\alpha$ expression $(\mathrm{P}=0.28)$; however, HIF-1 $\alpha$ was associated with tumor size and PgR levels. HIF-1 $\alpha$ expression increased with a larger tumor size $(\mathrm{r}=0.27 ; \mathrm{P}=0.008)$ and decreased PgR expression ( $r=-0.26 ; \mathrm{P}=0.0002)$.

Axillary nodal status and SUVmax. The $\mathrm{IQR}_{\mathrm{M}}$ of axillary nodal SUVmax was 2.7. SUVmax according to nodal status is presented in Table III. Axillary SUVmax of N1 was statistically lower than N2 and N3 (P<0.0001) (Fig. 3).

Multiple regression analysis. Multiple regression analysis was performed to determine the association between SUVmax and independent factors affecting SUVmax (Table IV). The SUVmax of the axillary lymph nodes was only predicted by nodal status in multiple regression analysis (coefficient, 2.7; $\left.\mathrm{r}_{\text {partial }}=0.70 ; \mathrm{t}=9.1 ; \mathrm{r}^{2}=0.49 ; \mathrm{P}<0.0001\right)$.

\section{Discussion}

Various studies have demonstrated an association between FDG uptake in tumors and multiple prognostic indicators (22-24). Additional studies have evaluated the association among hypoxia, namely HIF-1 $\alpha$, and FDG uptake in breast
Table I. Breast cancer tumor characteristics.

\begin{tabular}{|c|c|c|}
\hline Characteristic & Number & $\%$ \\
\hline \multicolumn{3}{|l|}{ Grade } \\
\hline 1 & 5 & 16.3 \\
\hline 2 & 49 & 53.3 \\
\hline 3 & 28 & 30.4 \\
\hline \multicolumn{3}{|l|}{ Nodal status } \\
\hline No & 30 & 32.6 \\
\hline N1 & 28 & 30.4 \\
\hline N2 & 20 & 21.7 \\
\hline N3 & 14 & 15.2 \\
\hline \multicolumn{3}{|l|}{ Tumor size } \\
\hline $\mathrm{T} 1$ & 19 & 20.7 \\
\hline $\mathrm{T} 2$ & 64 & 69.6 \\
\hline $\mathrm{T} 3$ & 9 & 9.8 \\
\hline \multicolumn{3}{|l|}{ ER } \\
\hline Negative & 16 & 17.4 \\
\hline Positive & 76 & 82.6 \\
\hline \multicolumn{3}{|l|}{$\mathrm{PgR}$} \\
\hline Negative & 17 & 18.5 \\
\hline Positive & 75 & 81.5 \\
\hline \multicolumn{3}{|c|}{ ER Allred score } \\
\hline$<4$ & 20 & 21.7 \\
\hline$\geq 4$ & 72 & 78.3 \\
\hline \multicolumn{3}{|c|}{ PgR Allred score } \\
\hline$<4$ & 29 & 31.5 \\
\hline$\geq 4$ & 63 & 68.5 \\
\hline \multicolumn{3}{|l|}{ HER-2 } \\
\hline 0 & 41 & 44.6 \\
\hline 1 & 15 & 16.3 \\
\hline 2 & 13 & 14.1 \\
\hline 3 & 23 & 25 \\
\hline \multicolumn{3}{|l|}{ Ki-67 } \\
\hline$\leq 10 \%$ & 34 & 37 \\
\hline$>10 \%$ & 58 & 63 \\
\hline \multicolumn{3}{|l|}{$\mathrm{HIF}-1 \alpha$} \\
\hline Negative & 15 & 16.3 \\
\hline Positive & 77 & 83.7 \\
\hline
\end{tabular}

ER, estrogen receptor; PgR, progesterone receptor; HER-2, human epidermal growth factor receptor-2; HIF-1 $\alpha$, hypoxia inducible factor- $1 \alpha$.

cancer (25). To the best of our knowledge, no study has yet investigated the combined association between hypoxia, FDG uptake and other clinicopathological prognostic factors.

In the present study, univariate analysis identified that augmented SUVmax values were associated with a higher nuclear grade, larger tumor size, negative hormone receptor status, triple-negativity and high Ki-67 expression. The median SUVmax value was higher in HER-2-positive breast cancer, but this was not significant statistically $(\mathrm{P}=0.07)$. Conversely, 


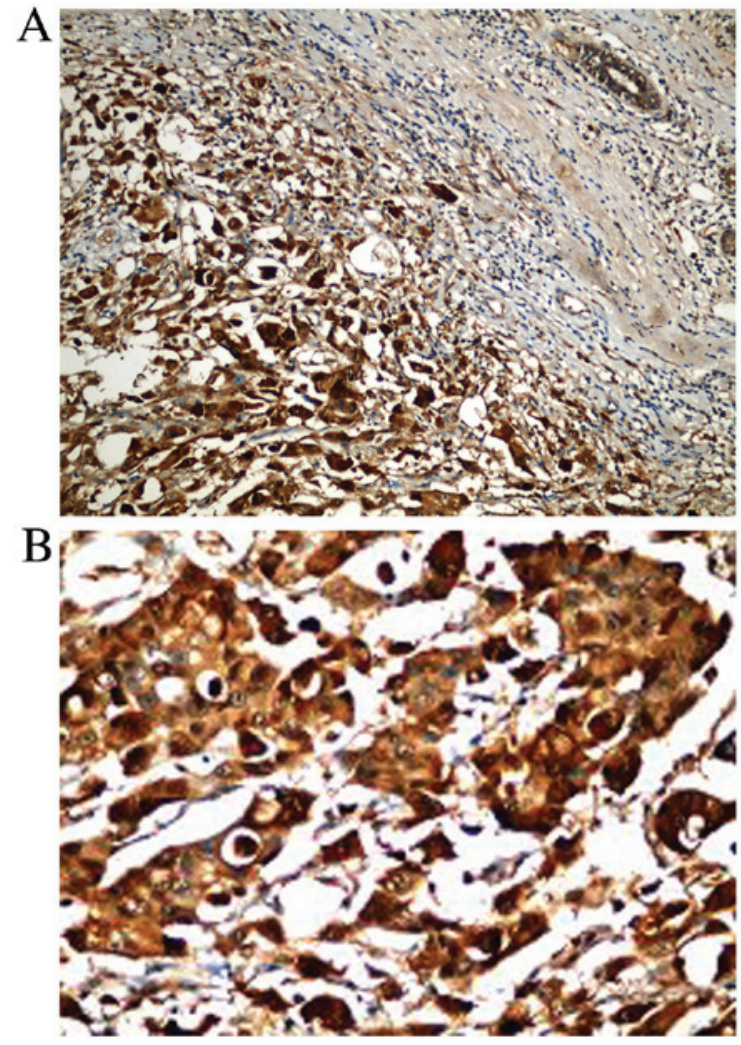

Figure 1. Immunohistochemical staining of breast cancer tissue. (A) Strong nuclear and cytoplasmic HIF-1 $\alpha$ positivity in the neoplastic breast carcinoma cells (left), and negative nuclear staining in the adjacent normal breast duct (upper right) (magnification, x200). (B) High power view of strong nuclear and cytoplasmic HIF-1 $\alpha$ expression in invasive breast carcinoma tissue (magnification, x400). HIF-1 $\alpha$, hypoxia induciblefactor- $1 \alpha$.

there was no association observed between HIF-1 $\alpha$ expression and FDG uptake. Factors for tumor proliferation and metastasis were significantly associated with augmented SUVmax. Oshida et al (26) reported that high FDG uptake in breast tumors is associated with poor prognosis. Conversely, results regarding the link between tumor proliferation and FDG uptake in multiple tumors remains controversial $(27,28)$. On the other hand, in a number of previous studies positive associations were observed between proliferation rates and FDG uptake in breast cancer $(15,16,22,25,29,30)$. The present study is consistent with this, as $\mathrm{Ki}-67$ expression and tumor size were considered independent factors for SUVmax in breast cancer according to multivariate regression analysis. Several studies have produced contradictory results, with some demonstrating a correlation between FDG uptake and tumor size $(16,17,30,31)$, while others have not had consistent results $(14,15,22,23,32)$.

Tumor and axillary lymph node grade are major predictive factors for breast cancer. In the present study, the most significant correlation was observed between SUVmax and tumor grade $(\mathrm{P}=0.001)$, which is consistent with previous studies $(16,17,26,30,33,34)$. Additionally, multiple regression analysis performed in current study demonstrated that the SUVmax of axillary lymph nodes was only predicted by nodal status (coefficient, 2.7; $\mathrm{r}_{\text {partial }}=0.70 ; \mathrm{t}=9.1 ; \mathrm{r}^{2}=0.49 ; \mathrm{P}<0.0001$ ). Song et al (12) reported that axillary nodal SUVmax on pretreatment FDG-PET may be an independent factor for
Table II. Univariate analysis of median SUVmax for different tumor characteristics.

\begin{tabular}{|c|c|c|}
\hline Characteristic & Median SUVmax (IQR) & P-value \\
\hline \multicolumn{3}{|l|}{ ER } \\
\hline Negative & $9.6(4.0)$ & \multirow[t]{2}{*}{$0.004^{\mathrm{a}, \mathrm{c}}$} \\
\hline Positive & $6(6.2)$ & \\
\hline \multicolumn{3}{|l|}{ PgR } \\
\hline Negative & $9.8(3.3)$ & \multirow{2}{*}{$0.008^{\mathrm{a}, \mathrm{c}}$} \\
\hline Positive & $6(6.1)$ & \\
\hline \multicolumn{3}{|l|}{ ER Allred score } \\
\hline$<4$ & $9.2(3.6)$ & \multirow[t]{2}{*}{$0.01^{\mathrm{a}, \mathrm{c}}$} \\
\hline$\geq 4$ & $6(6.3)$ & \\
\hline \multicolumn{3}{|c|}{ PgR Allred score } \\
\hline$<4$ & $9.1(4.2)$ & \multirow[t]{2}{*}{$0.03^{\mathrm{a}, \mathrm{c}}$} \\
\hline$\geq 4$ & $5.9(6.1)$ & \\
\hline \multicolumn{3}{|l|}{ HER-2 } \\
\hline Negative & $5.7(6.6)$ & \multirow[t]{2}{*}{$0.07^{\mathrm{a}}$} \\
\hline Positive & $7.9(3.8)$ & \\
\hline \multicolumn{3}{|l|}{ Triple-negative } \\
\hline Non-TN & $6.8(5.9)$ & \multirow[t]{2}{*}{$0.04^{\mathrm{a}, \mathrm{c}}$} \\
\hline $\mathrm{TN}$ & $10.1(3.6)$ & \\
\hline \multicolumn{3}{|l|}{ Ki-67 } \\
\hline$\leq 10 \%$ & $4.7(6.8)$ & \multirow[t]{2}{*}{$0.01^{\mathrm{a}, \mathrm{c}}$} \\
\hline$>10 \%$ & $7.8(5.5)$ & \\
\hline \multicolumn{3}{|l|}{ HIF- $1 \alpha$} \\
\hline Negative & $6.0(6.0)$ & \multirow[t]{2}{*}{$0.28^{\mathrm{a}}$} \\
\hline Positive & $7.8(5.5)$ & \\
\hline \multicolumn{3}{|l|}{ Grade } \\
\hline $1-2$ & $5.7(5.8)$ & \multirow[t]{2}{*}{$0.001^{\mathrm{a}, \mathrm{c}}$} \\
\hline 3 & $9.6(4.1)$ & \\
\hline \multicolumn{3}{|l|}{ Tumor size } \\
\hline $\mathrm{T} 1$ & $4.8(3.7)$ & \multirow[t]{3}{*}{$0.02^{\mathrm{b}, \mathrm{c}, \mathrm{c}}$} \\
\hline $\mathrm{T} 2$ & $7.8(6.2)$ & \\
\hline $\mathrm{T} 3$ & $7.9(3.8)$ & \\
\hline
\end{tabular}

${ }^{\mathrm{a}}$ Mann-Whitney U test; ${ }^{\mathrm{b}}$ Kruskal Wallis test; ${ }^{\mathrm{c}}<0.05$; ${ }^{\mathrm{d}} \mathrm{SUVmax}$ value of T1 is different from SUVmax value of T2 and T3. SUVmax, maximum standardized uptake value; IQR, interquartile range; ER, estrogen receptor; PgR, progesterone receptor; HER-2, human epidermal growth factor receptor-2; HIF-1 $\alpha$, hypoxia induciblefactor- $1 \alpha$.

disease relapse and prognosis in patients with invasive ductal carcinoma and axillary lymph node involvement.

Several studies have observed FDG uptake in invasive lobular cancer, which was reduced compared with other types of aggressive tumors $(14,15,23,30)$. This finding is explained by diffuse infiltration, lower tumor cell density, low levels of GLUT-1 and reduced proliferation $(23,35,36)$.

Although studies regarding hormone receptor expression and FDG uptake are inconsistent, the present study detected a significantly higher FDG uptake in ER- and PgR-negative tumors than positive ones $(\mathrm{P}=0.004$ and $\mathrm{P}=0.008$, respectively). Meanwhile, ER Allred score was identified to be an 
Table III. Axillary SUVmax according to nodal status.

\begin{tabular}{lcl}
\hline Nodal status & Median SUVmax (IQR) & \multicolumn{1}{c}{ Statistical significance } \\
\hline N0 & $0(0)$ & Statistically different from N1, N2 and N3 \\
N1 & $2.2(2.4)$ & Statistically different from N0, N2 and N3 \\
N2 & $5.7(5.4)$ & Statistically different from N0 and N1 \\
N3 & $5.8(6.3)$ & Statistically different from N0 and N1
\end{tabular}

The Kruskal Wallis test was used to determine statistical significance. SUVmax, maximum standardized uptake value; IQR, interquartile range.

Table IV. Multivariate model demonstrating the effects of different factors on SUVmax.

\begin{tabular}{lcrrr}
\hline & Coefficient & $\mathrm{r}_{\text {partial }}$ & $\mathrm{T}$ & P-value \\
\hline ER Allred score & -0.3322 & -0.2436 & -2.302 & 0.0238 \\
Ki-67 & 0.04052 & 0.2306 & 2.172 & 0.0327 \\
Size & 0.6996 & 0.2557 & 2.424 & 0.0175 \\
\hline
\end{tabular}

SUVmax, maximum standardized uptake value; ER, estrogen receptor.
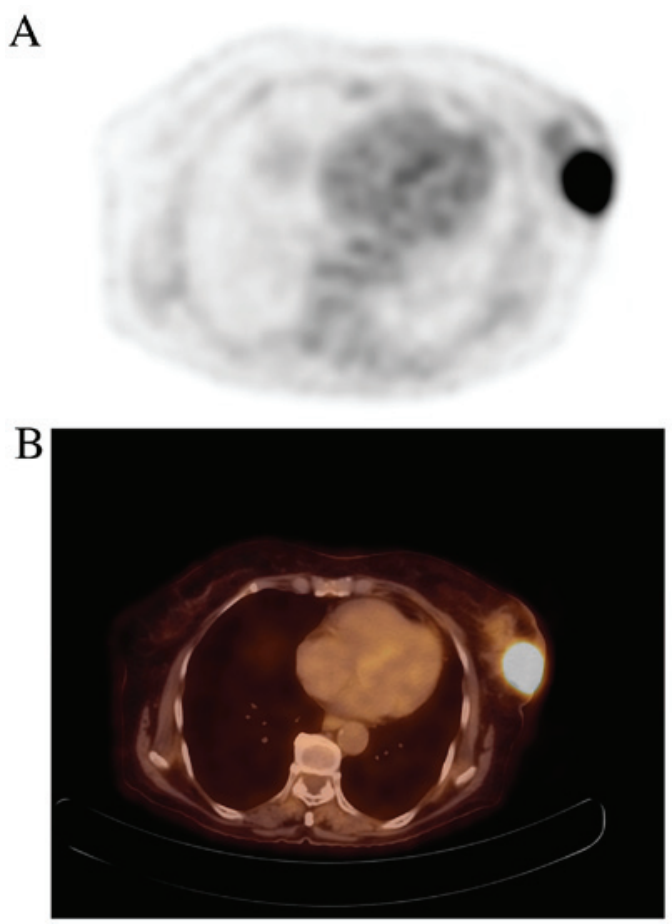

Figure 2. (A) FDG PET and (B) hybrid PET/computed tomography axial images demonstrating a left breast cancer lesion with notably increased FDG uptake (maximum standardized uptake value, 11.9) in a 76-year-old woman with invasive breast carcinoma (no special type). Histopathological and immunohistochemical features of the tumor were as follows: pT2 $(45 \mathrm{~mm})$; N0; histologic grade 3; ER-; PgR-; HER-2 3+++; and Ki-67, 70\%. FDG, ${ }^{18}$ F-fluorodeoxyglucose uptake; PET, positron emission tomography.

independent factor affecting SUVmax. A number of previous studies reported that there was correlation between hormone receptor status and SUVmax $(14,15,32,34,35,37)$. However,

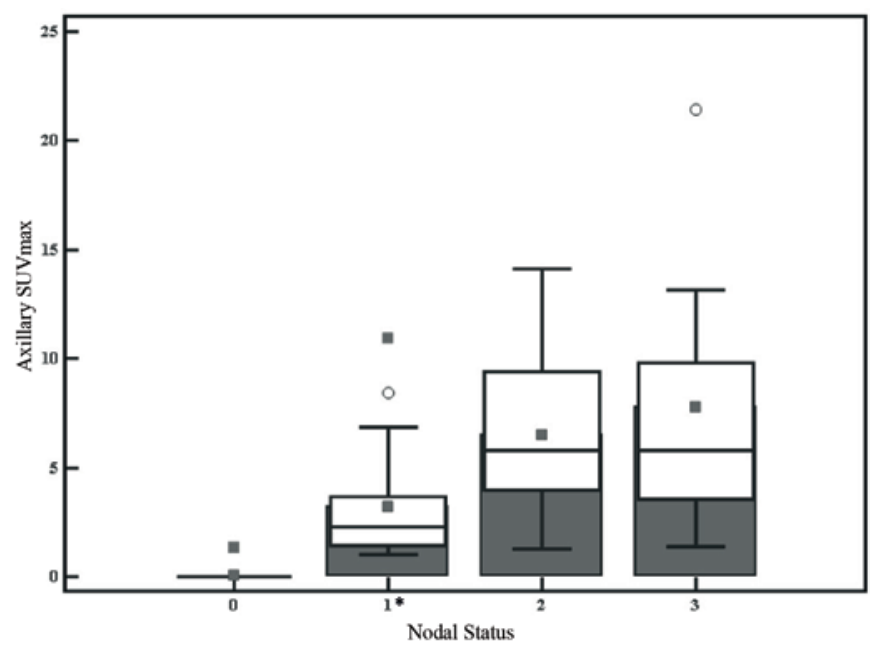

Figure 3. Axillary nodal SUVmax in the N1 stage were significantly lower than those in the $\mathrm{N} 2$ and N3 stages $\left({ }^{*} \mathrm{P}<0.0001\right)$. SUVmax, maximum standardized uptake values.

recent studies have demonstrated a positive association between SUVmax values and ER negativity in tumors $(30,32,37,38)$. Triple-negative tumors have been documented as more invasive and are known for their poor prognosis compared with non-triple negative tumors (37). The present study also observed that the triple-negative tumors had augmented SUVmax compared with the non-triple-negative disease $(\mathrm{P}=0.04)$, which is consistent with previous reports $(23,37)$.

Previously, several studies reported that there was a marked improvement in the survival of patients with HER-2 receptor-positive breast cancer due to the use of antibody treatment with trastuzumab (39-41). Although a few previous studies have observed an association between SUVmax and c-Erb-B2 positivity $(16,17)$, the current study did not identify a significant correlation, which is supported by a number of other studies $(15,32,37,42)$. This may suggest that HER-2 does not have any major effect on glycolytic pathways (23).

Intratumoral hypoxia has been demonstrated to lead to poor prognosis (43-45). Hypoxic tumors have been documented for their association with aggressiveness, augmented metastasis, and resistance to chemo and radiation therapy (43-45). Increased expression of HIF-1 $\alpha$ has been reported in a various forms of common cancer. Bos et al (8) observed that HIF-1 $\alpha$ was upregulated during breast pathogenesis following the identification of enhanced HIF-1 $\alpha$ levels in ductal carcinoma in situ and invasive cancer specimens. However, augmented levels were not observed in normal breast and ductal hyperplasia (8). 
Subsequently, Bos et al (25) investigated the association between FDG uptake and HIF-1 $\alpha$, GLUT-1, hexokinase I-II-III, vascular endothelial growth factor (VEGF), intratumoral microvessel density and mitotic index. Despite reporting a significant positive association with FDG uptake and GLUT-1 and hexokinase I, no correlation was observed between FDG uptake and HIF-1 $\alpha$ or other biomarkers (25). This was consistent with the results of the present study. Following investigation of Ki-67 expression through immunohistochemistry, Evans et al (46) suggested that hypoxic localized cell proliferation of tumors was decreased (46). In the current study, HIF-1 $\alpha$ levels were associated with tumor size and PgR negativity.

Clavo et al (47) examined FDG uptake in multiple types of carcinoma cells after varying the oxygen levels in vitro. An enhancement in FDG level was observed following moderate hypoxic treatment. Based on these results, it was suggested that hypoxia regulates FDG uptake $(28,47)$. Toba et al $(48)$ investigated the association between HIF-1 $\alpha$, GLUT-1, VEGF and FDG uptake in thymic epithelial tumors. The results demonstrated a moderate association between FDG uptake and the expression of HIF-1 $\alpha$ (48). Furthermore, Rajendran et al (9) examined the association between hypoxia and glycolysis with ${ }^{18} \mathrm{~F}$-fluoromisonidazole (FMISO) and FDG uptake on PET images in four diverse tumors, including breast cancer. A moderate association was identified between FDG and FMISO uptake in head and neck cancer, but no association was observed in other cancer forms, including breast cancer and glioblastoma (9).

In conclusion, the results of the current study suggested that increased FDG uptake was associated with various poor prognostic indicators, such as large tumor size, high tumor grade and Ki-67 expression, reduction in hormonal receptors, and triple-negative primary breast tumors. However, no assoication was identified between FDG uptake and HIF-1 $\alpha$ level. Although hypoxia impacts glycolysis, tumor hypoxia is a heterogeneous phenomenon. Therefore, there may be inconsistent patterns observed between glucose utilization and hypoxia. A major limitation of the present study may be that that only patients with invasive breast carcinoma were included. Thus, future studies may benefit from including a range of histological types, subsequently allowing a comparison between different types of breast cancer.

\section{References}

1. Siegel R, Naishadham D and Jemal A: Cancer statistics, 2012. CA Cancer J Clin 62: 10-29, 2012.

2. Knowles HJ and Harris AL: Hypoxia and oxidative stress in breast cancer. Hypoxia and tumourigenesis. Breast Cancer Res 3: 318-322, 2001.

3. Serganova I, Humm J, Ling C and Blasberg R: Tumor hypoxia imaging. Clin Cancer Res 12: 5260-5264, 2006.

4. Bos R, van der Groep P, Greijer AE, Shvarts A, Meijer S, Pinedo HM, Semenza GL, van Diest PJ and van der Wall E: Levels of hypoxia-inducible Factor-1alpha independently predict prognosis in patients with lymph node negative breast carcinoma. Cancer 97: 1573-1581, 2003.

5. Wang GL, Jiang BH, Rue EA and Semenza GL: Hypoxiainducible factor 1 is a basic-helix-loop-helix-PAS heterodimer regulated by cellular O2 tension. Proc Natl Acad Sci USA 92: 5510-5514, 1995.

6. Yu AY, Frid MG, Shimoda LA, Wiener CM, Stenmark K and Semenza GL. Temporal, spatial, and oxygen-regulated expression of hypoxia-inducible factor-1 in the lung. Am J Physiol 275: L818-L826, 1998.
7. Huang LE, Arany Z, Livingston DM and Bunn HF: Activation of hypoxia-inducible transcription factor depends primarily upon redox-sensitive stabilization of its apha subunit. J Biol Chem 271: 32253-32259, 1996.

8. Bos R, Zhong H, Hanrahan CF, Mommers EC, Semenza GL, Pinedo HM, Abeloff MD, Simons JW, van Diest PJ and van der Wall E: Levels of hypoxia-inducible factor-1 alpha during breast carcinogenesis. J Natl Cancer Inst 93: 309-314, 2001.

9. Rajendran JG, Mankoff DA, O'Sullivan F, Peterson LM, Schwartz DL, Conrad EU, Spence AM, Muzi M, Farwell DG and Krohn KA: Hypoxia and glucose metabolism in malignant tumors: Evaluation by [18F]fluoromisonidazole and [18F]fluorodeoxyglucose positron emission tomography imaging. Clin Cancer Res 10: 2245-2252, 2004.

10. Burgman P, Odonoghue JA, Humm JL and Ling CC: Hypoxiainduced increase in FDG uptake in MCF7 cells. J Nucl Med 42: 170-175, 2001.

11. Warburg O (ed): The Metabolism of Tumors. Richard R., Inc., New York, NY, pp129-169, 1931.

12. Song BI, Lee SW, Jeong SY, Chae YS, Lee WK, Ahn BC and Lee J: 18F-FDG uptake by metastatic axillary lymph nodes on pretreatment PET/CT as a prognostic factor for recurrence in patients with invasive ductal breast cancer. J Nucl Med 53: 13371344,2012

13. Czernin J and Phelps ME: Positron emission tomography scanning: Current and future applications. Annu Rev Med 53: 89-112, 2002

14. Avril N, Rosé CA, Schelling M, Dose J, Kuhn W, Bense S, Weber W, Ziegler S, Graeff $\mathrm{H}$ and Schwaiger M: Breast imaging with positron emission tomography and fluorine-18 fluorodeoxyglucose: Use and limitations. J Clin Oncol 18: 3495-3502, 2000.

15. Buck A, Schirrmeister H, Kühn T, Shen C, Kalker T, Kotzerke J, Dankerl A, Glatting G, Reske S and Mattfeldt T: FDG uptake in breast cancer: Correlation with biological and clinical prognostic parameters. Eur J Nucl Med Mol Imaging 29: 1317-1323, 2002.

16. Ueda S, Tsuda H, Asakawa H, Shigekawa T, Fukatsu K, Kondo N, Yamamoto M, Hama Y, Tamura K, Ishida J, et al: Clinicopathological and prognosti relevance of uptake level using 18F-fluorodeoxyglucose positron emission tomography/ computed tomography fusion imaging (18F-FDG PET/CT) in primary breast cancer. Jpn J Clin Oncol 38: 250-258, 2008.

17. Sanli Y, Kuyumcu S, Ozkan ZG, Ișİk G, Karanlik H, Guzelbey B, Turkmen C, Ozel S, Yavuz E and Mudun A: Increased FDG uptake in breast cancer is associated with prognostic factors. Ann Nucl Med 26: 345-350, 2012.

18. Fitzgibbons PL, Page DL, Weaver D, Thor AD, Allred DC, Clark GM, Ruby SG, O'Malley F, Simpson JF, Connolly JL, et al: Prognostic factors in breast cancer. Collage of american pathologists consensus statement 1999. Arch Pathol Lab Med 124: 966-978, 2000.

19. Lakhani SR, Ellis IO, Schnitt SJ, Tan PH and van de Vijver MJ: WHO Classification of tumours of the breast. 4th edition. IARC, Lyon, France, 2012.

20. Dales JP, Garcia S, Meunier-Carpentier S, Andrac-Meyer L, Haddad O, Lavaut MN, Allasia C, Bonnier P and Charpin C: Overexpression of hypoxia-inducible factor HIF-1 alpha predicts early relapse in breast cancer: Retrospective study in a series of 745 patients. Int J Cancer 116: 734-739, 2005.

21. Cohen DA, Dabbs DJ, Cooper KL, Amin M, Jones TE, Jones MW, Chivukula M, Trucco GA and Bhargava R: Interobserver agreement among pathologists for semiquantitative hormone receptorscoring in breast carcinoma. Am J Clin Pathol 138: 796-802, 2012

22. Koolen BB, Vrancken Peeters MJ, Wesseling J, Lips EH, Vogel WV, Aukema TS, van Werkhoven E, Gilhuijs KG, Rodenhuis S, Rutgers EJ and Valdés Olmora RA: Association of primary tumour FDG uptake with clinical, histopathological and molecular characteristics in breast cancer patients scheduled for neoadjuvant chemotherapy. Eur J Nucl Med Mol Imaging 39: 1830-1838, 2012.

23. Groheux D, Giacchetti S, Moretti JL, Porcher R, Espié M, Lehmann-Che J, de Roquancourt A, Hamy AS, Cuvier C, Vercellino L and Hindié E: Correlation of high 18F-FDG uptake to clinical, pathological and biological prognostic factors in breast cancer. Eur J Nucl Med Mol Imaging 38: 426-435, 2011.

24. Heudel P, Cimarelli S, Montella A, Bouteille C and Mognetti T: Value of PET-FDG in primary breast cancer based on histopathological and immunohistochemical prognostic factors. Int J Clin Oncol 15: 588-593, 2010. 
25. Bos R, van Der Hoeven JJ, van Der Wall E, van Der Groep P, van Diest PJ, Comans EF, Joshi U, Semenza GL, Hoekstra OS, Lammertsma AA and Molthoff CF: Bioglogic correlates of (18) fluorodeoxyglucose uptake in human breast cancer measured by positron emission tomography. J Clin Oncol 20: 379-387, 2002.

26. Oshida M, Uno K, Suzuki M, Nagashima T, Hashimoto $H$, Yagata H, Shishikura T, Imazeki K and Nakajima N: Predicting the prognoses of breast carcinoma patients with positron emission tomography using 2-deoxy-2-fluoro[18F]-D-glucose. Cancer 82: 2227-2234, 1998.

27. Buck AC, Schirrmeister HH, Guhlmann CA, Diederichs CG, Shen C, Buchmann I, Kotzerke J, Birk D, Mattfeldt T and Reske SN: Ki-67 immunostaining in pancreatic cancer and chronic active pancreatitis: Does in vivo FDG uptake correlate with proliferative activity? J Nucl Med 42: 721-725, 2001.

28. Higashi K, Clavo AC and Wahl RL: Does FDG uptake measure proliferative activity of human cancer cells? In vitro comparison with DNA flow cytometry and tritiated thymidine uptake. J Nucl Med 34: 414-419, 1993

29. Simpson JF, Gray R, Dressler LG, Cobau CD, Falkson CI, Gilchrist KW, Pandya KJ, Page DL and Robert NJ: Prognostic value of histologic grade and proliferative activity in axillary node-positive breast cancer: Results from the Eastern Cooperative Oncology Group Companion Study, EST 4189. J Clin Oncol 18 : 2059-2069, 2000.

30. Gil-Rendo A, Martínez-Regueira F, Zornoza G, GarciaVelloso MJ, Beorlegui C and Rodriguez-Spiteri N: Association between [18F]fluorodeoxyglucose uptake and prognostic parameters in breast cancer. Br J Surg 96: 166-170, 2009.

31. Nakajo M, Kajiya Y, Kaneko T, Kaneko Y, Takasaki T, Tani A, Ueno M, Koriyama C and Nakajo M: FDG PET/CT and diffusion-weighted imaging for breast cancer: Prognostic value of maximum standardized uptake values and apparent diffusion coefficient values of the primary lesion. Eur J Nucl Med Mol Imaging 37: 2011-2020, 2010.

32. Osborne JR, Port E, Gonen M, Doane A, Yeung H, Gerald W, Cook JB and Larson S: 18F-FDG PET of locally invasive breast cancer and association of estrogen receptor status with standardized uptake value: Microarray and immunohistochemical analysis. J Nucl Med 51: 543-550, 2010.

33. Berriolo-Riedinger A, Touzery C, Riedinger JM, Toubeau M, Coudert B, Arnould L, Boichot C, Cochet A, Fumoleau P and Brunotte F: [18F]FDG-PET predicts complete pathological response of breast cancer to neoadjuvant chemotherapy. Eur J Nucl Med Mol Imaging 34: 1915-1924, 2007.

34. Kumar R, Chauhan A, Zhuang H, Chandra P, Schnall M and Alavi A: Clinicopathologic factors associated with false negative FDG-PET in primary breast cancer. Breast Cancer Res Treat 98: 267-274, 2006

35. Crippa F, Seregni E, Agresti R, Chiesa C, Pascali C, Bogni A, Decise D, De Sanctis V, Greco M, Daidone MG and Bombardieri E: Association between [18F]fluorodeoxyglucose uptake and postoperative histopathology, hormone receptor status, thymidine labelling index and p53 in primary breast cancer: A preliminary observation. Eur J Nucl Med 25: 1429-1434, 1998.
36. Avril N, Rosé CA, Schelling M, Dose J, Kuhn W, Bense S, Weber W, Ziegler S, Graeff $\mathrm{H}$ and Schwaiger M: Breast imaging with positron emission tomography and fluorine-18 fluorodeoxyglucose: Use and limitations. J Clin Oncol 18: 3495-3502, 2000.

37. Kim BS and Sung SH: Usefulness of 18F-FDG uptake with clinicopathologic and immunohistochemical prognostic factors in breast cancer. Ann Nucl Med 26: 175-183, 2012.

38. Mavi A, Cermik TF, Urhan M, Puskulcu H, Basu S, Yu JQ, Zhuang H, Czerniecki B and Alavi A: The effects of estrogen, progesterone, and C-erbB-2 receptor states on 18F-FDG uptake of primary breast cancer lesions. J Nucl Med 48: 1266-1272, 2007.

39. Romond EH, Perez EA, Bryant J, Suman VJ, Geyer CE Jr, Davidson NE, Tan-Chiu E, Martino S, Paik S, Kaufman PA, et al: Trastuzumab plus adjuvant chemotherapy for operable HER2positive breast cancer. N Engl J Med 353:1673-1684, 2005.

40. Piccart M, Lohrish C, Di Leo A and Larsimont D: The predictive value of HER 2 in breast cancer. Oncology 61 (Suppl 2): 73-82, 2001.

41. Gonzalez-Angulo AM, Hortobagyi GN and Esteva FJ: Adjuvant therapy with trastuzumab for HER-2/neu-positive breast cancer. Oncologist 11: 857-867, 2006.

42. Ikenaga N, Otomo N, Toyofuku A, Ueda Y, Toyoda K, Hayashi T, Nishikawa $\mathrm{K}$ and Tanaka M: Standardized uptake values for breast carcinomas assessed by fluorodeoxyglucose-positron emission tomography correlate with prognostic factors. Am Surg 73: 1151-1157, 2007.

43. Spence AM, Muzi M, Graham MM, O'Sullivan F, Krohn KA, Link JM, Lewellen TK, Lewellen B, Freeman SD, Berger MS and Ojemann GA: Glucose metebolism in human malignant gliomas measured quantitatively with PET, 1-[C-11]glucose and FDG: Analysis of the FDG lumped constant. J Nucl Med 39: 440-448, 1998

44. Kallinowski F, Schlenger KH, Kloes M, Stohrer M and Vaupel P: Tumor blood flow: The principal modulator of oxidative and glycolytic metablism and of the metabolic micromilieu of human tumor xenografts in vivo. Int J Cancer 44: 266-272, 1989.

45. Fleming IN, Manavaki R, Blower PJ, West C, William KJ, Harris AL, Domarkas J, Lord S, Baldry C and Gilbert FJ: Imaging tumour hypoxia with positron emission tomography. $\mathrm{Br}$ J Cancer 112: 238-250, 2015.

46. Evans SM, Hahn SM, Magarelli DP and Koch CJ: Hypoxic heterogeneity in human tumors: EF5 binding, vasculature, necrosis and proliferation. Am J Clin Oncol 24: 467-472, 2001.

47. Clavo AC, Brown RS and Wahl RL: Fluorodeoxyglucose uptake in human cancer cell lines is increased by hypoxia. J Nucl Med 36: 1625-1632, 1995.

48. Toba H, Kondo K, Sadohara Y, Otsuka H, Morimoto M, Kajiura K, Nakagawa Y, Yoshida M, Kawakami Y, Takizawa H, et al: $18 \mathrm{~F}$-fluorodeoxyglucose positron emission tomography/ computed tomography and the relationship between fluorodeoxyglucose uptake and the expression of hypoxia-inducible factor-1 $\alpha$, glucose transporter-1 and vascular endothelial growth factor in thymic epithelial tumours. Eur J Cardiothorac Surg 44: $105-112,2013$. 